\title{
Religious Evidence-Based Spiritual Self-Care Guidelines in Anger Management \\ Asadzandi $\mathbf{M}^{1 *}$ and Eskandari $\mathrm{AR}^{2}$
}

${ }^{1}$ Department of Anaesthesiology, University of Medical Sciences, Baqiyatallah, Iran

${ }^{2}$ School of Nursing, University of Medical Sciences, Baqiyatallah, Iran

\section{Abstract}

Background and Aims: Due to the increasing prevalence of aggression and its destructive impact on various aspects of health, familiarity with simple and practical methods of anger management is necessary. This study aimed to design and validate religious evidence-based spiritual self-care guidelines in anger management.

Methods: In an evolutionary research, focused on the question of "What are the guidelines of anger managing?" based on the religious and scientific evidence-based approach, the evidence was first reviewed by PICO method. Based on Sattler Model, instructions were extracted. Validity of instructions in three Delphi rounds was investigated with survey seminary and university professors. The instructions ability to apply, in focus groups meetings with nurses, was investigated. Quality of new guidelines was desirable by Agree and Glia questionnaire.

Findings: The aim of the therapeutic interventions in scientific psychology is reducing emotional impulses and physiological arousal by increasing the awareness of individuals towards anger and its control techniques. In addition to treating the excitement of anger, Islam addresses the individual to an endurance that is the opposite of anger. Religious behavioural and cognitive anger management guidelines provide spiritual care that can easily be done by client in schedule of daily pastoral self-care.

Conclusion: Simple, intelligible and practical religious evidence-based guidelines can be used to strengthen selfcontrol and daily self-calculation. In addition to reducing aggression, they promote the spiritual well-being of individuals and prevent the social and psychosocial outcomes of anger.

Keywords: Guideline; Anger management; Spiritual; Self-care

\section{Introduction}

The increased prevalence of psychiatric disorders in the world [1] and the remarkable trend of these diseases in the 15-60 years old of Iranian population in recent years, from $21.5 \%$ in 2012 [2] to $25 \%$ in 2014 [3] and 34\% in 2016 [4] as well as the absence of "psychiatric intensive care units" in the Iranian hospitals, in addition to the development of psychosomatic diseases from $40 \%$ [5] to 50\%, has been emphasized on "The Necessity of Improving Mental Health of the Country with the Priorities of the Health System " as an effective way to reduce mental disorders.

One of the most common psycho-spiritual disorders is the high-risk behaviour of aggression (deliberate damage to oneself or others) due to the "thrill of anger", which involves four major behavioural reactions: physical confrontation) conflict), vilification, passive aggression and avoidance [6]. Reports indicate that $31 \%$ of physical confrontation prevalent in Iranian population aged 15-64 [7], and 45.6\% of conflict and $10.5 \%$ of self-injury among young people [8]. These problems, in addition to spending part of the government's credits, have caused social outcomes, which have urged research into: anger management methods.

Research has shown that: environmental variables such as: noise and air pollution, vulnerability, disability, self-efficacy loss by attacking self-esteem through humiliation, Criticize, nudge, along with social damage such as: blasphemy, physical abuse, verbal ridicule, seeing violent content in media, violent computer games, has caused aggression in various forms as a high risk behaviour, among healthy people in the international community $[9,10]$. Patients also show anger and aggression in the Grief process, as a spiritual response to the crisis of disease [11], especially when faced with death, because of the fear and feeling of loneliness, along with increasing physiological excitations, pain, damage to nervous areas, Serotonin hormone deficiency in the brain [9]. Scientific textbooks describe anger as a secondary sensation from fear and anxiety, Shame and embarrassment, Sorrow, Cognitive errors and defective thoughts [9]. For this reason, the anger is one of the important nursing diagnoses that need care on the NANDA Diagnostic List [12]. Because of anger disturbs people's mental health such as : Ability to adapt to the environment, control emotional reactions in interpersonal interactions, resist the inevitable failures of life, lack of symptoms of disability, and the ability to communicate constructively with others $[13,14]$ and It also damages the spiritual health of individuals [15].

The research carried out in Iran in the last three decades is based entirely on the cognitive-behavioural approach to the Nova quip's anger theory. The cognitive theory is based on the connection of the components of thinking, feeling and behaviour, to reduce the likelihood of aggressive behaviours by increasing awareness of the symptoms of anger and control techniques training. Anger training workshops are taught:- Cognitive preparation through the training of the nature of anger, its causes and effects, and how people respond to

*Corresponding author: Asadzandi M, Department of Anaesthesiology, School of Nursing, Research fellow of Medicine and Religion Research Centre, University of Medical Sciences, Baqiyatallah, Tehran, Iran, Tel: +982182483131; E-mail: zandi498@yahoo.com

Received April 02, 2018; Accepted April 09, 2018; Published April 16, 2018

Citation: Asadzandi M, Eskandari AR (2018) Religious Evidence-Based Spiritual Self-Care Guidelines in Anger Management. J Health Educ Res Dev 6: 255. doi: 10.4172/2380-5439.1000255

Copyright: $\odot 2018$ Asadzandi M, et al. This is an open-access article distributed under the terms of the Creative Commons Attribution License, which permits unrestricted use, distribution, and reproduction in any medium, provided the original author and source are credited. 
anger-Acquiring skills-practice coping strategies-Improving internal speech-relaxation technique-daring. Application and tracking of taught skills in role-playing hypothetical situations is done [16]. Another category of interventions were based on the Smith intervention method, with an emphasis on the relationship between the elderly and the children whit three components in the multiple educational models: conceptualization, acquisition of skills and practice, follow-up [17]. Despite the fact that most Iranians are Muslims or followers the Abrahamic religions, and all religions emphasis on daily evaluation of intentions and behaviours, as a lifestyle, and management of anger along with the sexual desire from the time of duty as a spiritual selfcare, but unfortunately, designing and verifying religious spiritual guidelines as a community-based approach has never been considered by Muslims researchers. Therefore, to address this gap, the present study aimed to "design and validate religious evidence-based spiritual self-care guidelines in anger management".

\section{Methods}

This evolutionary study [18] has focused on this question: "what are the instructions for spiritual care of anger management."? The following stages were carried out to promote and complete the available knowledge by using a systematic, scientific, and justifiable process.

\section{Specifying the needs, aim, and population}

In this regard, initially, all the spiritual care instructions available in ministry of health and treatment, about anger and aggression (predisposed to self-invasion, predisposed to invasion, disturbance in protection, etc.) were selected and their quality was examined by Agree and Glia standard tools [19].

\section{Reviewing the evidences}

Searching and studying articles were done based on the PICO method during the following stages:

- $\mathrm{P}$ [Patient, Population]: determining the clients' characteristics and his related health issue.

- I [Intervention]: determining desired intervention or treatment measure (one specific aspect of health care, which should be done by a nurse or health care team) in different levels such as therapeutic, preventive, diagnostic, and organizational interventions.

- C [Comparison]: explaining another intervention, which can be compared with the desired intervention? The intervention is selective and can be removed from the clinical question.

- [Outcome]: results achieved form performing a specific intervention in the study.

\section{Inclusion criteria for selecting evidences and articles included:}

- Persian or English articles that focus on nursing spiritual care available in internal and external information databases (Request PubMed, Google Scholar, Elsevier, SID, Cochrane, Magi ran).

- Articles have to be written in 2005-2015 with the key words: anger, aggression, conflict, self-harm.

- Essay based on evidence-based pyramid in order of priority from the systematic review studies, meta-analysis, clinical trial tests, cohort, case study, case report, laboratory studies, as well as opinions of specialists and experts [20].

- According to the Inclusion criteria and "targeted sampling", out of
95 full paper 48 papers were selected that formed the sample size of the study.

- Verses interpretations should have been collected from the authentic reference books.

- Islamic evidences were taken from the verses and narrations related to the word "wrath", using al-Mu'ayyim, authentic Shi'a commentary books, related reliable hadiths from Bihar al-Anwar, adequate principles, ethics in the Qur'an, narratives of the Hadith of Imam Sadiq (peace be upon him), the Book of Sins, the Sound Heart and Ethics.

- Articles that did not have entry criteria were not included in the study from the beginning, so there were no exclusion criteria in this study.

\section{Design new guidelines based on Settler model, which is including the following issues}

- Preparation: In this phase, the goals and problems of aggressive clients were identified [21].

- Accreditation: In three Delphi rounds, at least 10 professors from the seminaries, nursing professors, psychologists, clinical nurses and educational coaches medical sciences universities of Iran, Tehran and Shahid Beheshti were consulted for content verification. And his views were considered as an expert group.

- Comparative study: determining the practicality of the instructions and assessing benefits and dangers for the clients, was done in the focus group, consisted of at least 15 nurses with B.A or M.A of nursing.

- Application: the way of using these instructions were determined during focus group discussions. Final instructions for operation were provided in the form of operating codes [22].

\section{Performing and evaluating instructions}

Clinical performance and evaluation were not possible in this study $[23,24]$.

\section{Findings}

Due to the diverse causes of anger and variability in the symptoms of anger, sometimes the client and family do not seek to cure this problem (Table 1). This can have other consequences, such as: feelings of hatred and revenge, hostility, social isolation, Grudge and cruelty [11]. However, in other countries in the world, people with aggression are being admitted to mental health intensive care units [25].

\section{Discussion}

Spiritual self-care guidelines, based on the development of the relationship with God and the improvement of communication with others, create self-awareness, self-control, and self-efficacy, which are not similar to therapeutic interventions. The purpose of therapeutic interventions in aggressive clients are: reduction of emotional excitement, physiological arousal and increasing the awareness about the outcomes of anger [16, 26], which is usually done, in the form of anger management workshops, in diverse target groups, by cognitive reconstruction, physiological arousal control and behavioural skills practice $[27,28]$. Workshops are implemented by using Beck's cognitive reconstruction techniques, Alice's rational and emotional techniques, Training for daring and social skills, regular desensitization, and calm training [29]. Reviewing the articles showed similarity between the 
Citation: Asadzandi M, Eskandari AR (2018) Religious Evidence-Based Spiritual Self-Care Guidelines in Anger Management. J Health Educ Res Dev 6: 255. doi: 10.4172/2380-5439.1000255

Page 3 of 5

\begin{tabular}{|c|c|}
\hline \multicolumn{2}{|l|}{ Instruction } \\
\hline Nursing Diagnosis & $\begin{array}{l}\text { Mood disorder: "wrath "related to: desire for revenge, ridicule and hypocrisy, greed, war and fights, non-criticism, selfishness, } \\
\text { over-liking of the material manifestations of the world, impure hearts }\end{array}$ \\
\hline Evaluation criteria & contention ,Malice, Cursing, Shout, the clash, Assault, Regret and doom of conscience \\
\hline \multicolumn{2}{|r|}{ Nursing intervention } \\
\hline 1 & Assessing client's beliefs \\
\hline 2 & Investigating the causes of anger (fear, grief, etc.) \\
\hline \multirow{8}{*}{ Self-awareness } & investigating the previous methods of anger control by the client \\
\hline & Avoid evacuation of anger: like a scream, crying, punching or self-righteousness \\
\hline & Performing respiratory techniques \\
\hline & Distracting the mind by imagination \\
\hline & Recommended to get away from the place and change the environment \\
\hline & Round off the causes of anger \\
\hline & Avoid people who are angry and meet with patient people \\
\hline & Avoid environments that create anger \\
\hline \multirow{10}{*}{$\begin{array}{l}\text { Development of relationship with } \\
\text { God }\end{array}$} & Recommend to seek refuge in God \\
\hline & Recommend to mention God \\
\hline & Advice to Salavat on the Prophet \\
\hline & Advice on long prostheses \\
\hline & $\begin{array}{l}\text { Repeat the prayers of the Prophet Younis with God in the heart of the whale Remembering, the ugliness of anger and its harmful } \\
\text { consequences }\end{array}$ \\
\hline & Remind the blame of religion about aggression and their punishment on the Day of Judgment \\
\hline & Spiritual Skills Training: Forgiveness and forgiveness Optimism, Hope, Trust, Patience \\
\hline & Attention to the problems of life as divine test \\
\hline & Performing a storytelling to reinforce divine belief and divinity \\
\hline & Recommend to be afraid of God's wrath \\
\hline \multirow{3}{*}{ Social awareness } & Recommend to pass away from others' mistakes \\
\hline & Recommend to accept others and tolerate others \\
\hline & It's advisable not to hurry in judging and scheduling things \\
\hline \multirow{12}{*}{ Self-management } & Advice to silence when angry \\
\hline & Advice on positive conversations with yourself: like "I can control my anger," "do not care", "calm down" \\
\hline & Advice on losing and hugging someone who is angry with her \\
\hline & Advised to change the state, from standing to sitting and sitting to sleep \\
\hline & Advise to look at your face in the mirror when angry \\
\hline & Recommend to accept yourself with all the good and bad \\
\hline & Advice for ablution and bathing with cold water \\
\hline & $\begin{array}{l}\text { Advice on lifestyle modification (with adequate sleep, exercise and physical exercises and techniques for lethargy, proper } \\
\text { nutrition, balance in daily programs, daily relaxation) }\end{array}$ \\
\hline & Self-suggestion with sentences such as: "The world does not want to hurt me!" "I face a life challenge" \\
\hline & $\begin{array}{l}\text { Advice to exclude false beliefs: "Everything should be according to my desire." I am a very demanding person. "My actions and } \\
\text { behavior must always be endorsed by others. }\end{array}$ \\
\hline & Recommend to try, give yourself a pat on \\
\hline & Recommendation to replace logical thinking \\
\hline Self- Efficacy & Carrying out daily spiritual self-care \\
\hline Self-control & $\begin{array}{l}\text { Doing self-control for forty days (writing down the number of your angry ones per day, self-regulating or punishing yourself and } \\
\text { repeating this action) }\end{array}$ \\
\hline
\end{tabular}

Table 1: Instruction Number 908 Moral Distresses (Anger).

overall content of the training workshops. The differences are most often related to the number and duration of meetings, samples, details of the sessions, outcomes, or the method of study. Unfortunately, the review did not reveal a study on the design and validation of religious evidence-based guidelines for anger management [30].

In all therapies, an aggressive person should attend at workshops meetings or in severe conditions should be admitted to the psychiatric intensive care unit [25]. They will be treated by a therapist but, unfortunately, there is no way for daily self-care [31]. While Abrahamic religious evidence emphasizes on lifestyle modification, by detailed planning (daily Self- calculation Method), Make a bet each morning, Self-care during the day, Evaluation of verbal and nonverbal behaviours, thoughts and feelings at the end of the day, Then punish and repent of the mistakes and decide to stay away from them, on all days of life $[32,33]$. They emphasizing spiritual self-care, regard individuals as responsible for their care, provide daily and continuous programs consistent with the beliefs and values of their followers throughout their lives, these points were not seen in scientific evidence. [34,35].

This research has been able to address the issue of "anger managing "from two perspectives (religious and scientific). Consider the Quran and narratives as the viewpoints of the experts in the evidence pyramid. Based on the religious spirituality of the Abrahamic religions, emphasizes the correction of the relationship with God, which will improve relationship with himself, people and the creations, and to carry out affairs with the intention of pleasing God, as a source of motivation [36]. 
The scientific workshops of anger management runs:

- Definition of anger,

- Explain the causes of it,

- Reporting stimuli to create anger in daily life,

- Leave the place,

- Teaching the technique of paying attention (thinking distortion by writing, remembering poetry, image or memories of joy, with),

- Creating an emotional self-awareness about physical changes during anger,

- Coping Strategies: Legation Technique, Exercise,

- Teach problem solving skills,

- Ways to counteract negative thoughts by stopping thought,

- Using rational thoughts,

- Talking to the empty seat,

- Positive self-talk,

- Role play.

At the end of the training, while examining the strengths of the defeat, they will determine the achievable and realistic goals and use of future useful strategies. These are consistent with the present study [37]. Emotional intelligence training of "Bradbury \& Graves' program" based on the negative relationship between aggression and emotional intelligence is implemented in anger workshop. By teaching four components of emotional intelligence including: self-awareness, self-management, awareness of other people's excitements or social awareness and relationship management.

The workshop program will be held in eight sessions:

- Define the excitement and identify its types,

- Identify facial expressions and thoughts with different types of emotions,

- Investigate the relationship between thoughts, emotions and behavior through practical examples,

- How to identify emotions in others,

- Different ways of expressing emotions and the need for managing emotions,

- Thrill control includes emotional prediction and the first emotional symptoms,

- Excitement control by changing position, relaxation and emotional keywords,

- Teaching Emotional Problem Solving Methods and Properly Expressions of Excitement [38].

Anger management workshops in the cognitive dimension also emphasize the increase of specific skills to change behaviour and thoughts, to control severe emotional responses in a self-control framework, to acquire skills for modulating the severity, duration and frequency of anger, and the emergence of non-aggressive and community-accepted responses [30-39]. Spiritual care, pay attention to spiritual skills training, the Day of Judgment as motivating factor, which has been neglected in the science.

\section{Conclusion}

Increasing violence in different societies has made it essential for health care personnel and clients to become familiar with spiritual care instructions. The use of simple, intelligible and practical spiritual instruction through the correction of the four dimensions of human communication and the impact of thoughts on emotions and behaviour can be easily incorporated into the self-care plan. The guidelines can be used to strengthen self-control in daily self-calculation.

\section{Acknowledgements}

In this regard, the research group thanks and appreciates all professors who helped us in conducting this study.

\section{Conflicts of Interest}

This article is taken from MA thesis with P.340.200 number and IR.BMSU REC.1394010 ethical committee and there is no conflict of interest in its performance.

\section{References}

1. Aghamohamedyan HR, Nickhah P (2004) Evaluate the effectiveness of cognitive communication skills behavioral group training in marital satisfaction. The first Congress of Pathology's family. Tehran: University Martyr Behest.

2. Noorbala A, Yasami MT (2012) Assessment of mental health in people over 15 years in the Islamic Republic of Iran. Hakim Research Journal 5: 1-10.

3. Jalili SA (2018) Symposium "Day without Depression" in 2014. Available from March 03, 2018

4. Mohsen Bandpi A (2018) Head of the Welfare Organization of Iran. first scientific congress on social determinants of health, Shiraz, in 2016. Available from: March 30, 2018.

5. Rafati F, Sharif F, Ahmadi J, Shafiee N (2010) The impact of mental health on their academic achievement. Journal of Sadoughi University Yazd 8: 81-82.

6. Taylor JL, Navaco R (2005) Anger treatment for people with developmentalities A theory evidence and manual based approach. John Wiley \& Sons, p: 274

7. Maleki S, Fallahi Khoshknab M, Rahgoui A, Rahgozar M (2011) The effect of anger management training on aggression of male students $12-15$ years old Iran Journal of Nursing 24: 26-35.

8. Jalili A (2011) Training in groups on aggression of 12-15 years old male students. IJN 24: 26-35.

9. Asadzandi M, Ebadi A (2014) Design and determining the psychometric properties of the questionnaire spiritual response (emotional reactions) of patient to disease. School of Nursing, University of Medical Sciences.

10. Sadvk BJ, Sadvk VA, Pedro R (2015) Summary Kaplan Psychiatry and Behavioral Sciences Sadvk/Clinical Psychiatry. Translator: Foster F. 11th edition.

11. Smith M, Oleary S (2007) Multivariate models of mothers and fathers aggression toward their children. J Consult Clin Psycholog 75: 739-751.

12. Asadzandi M (2007) Clients and Patients' Spiritual Nursing Diagnosis of the Sound Heart Model. J Communit Med Health Edu 7: 2-6.

13. American Nursing Association (2017) Definition of nursing. Washington DC American Nursing Publishing.

14. Farahbakhsh S, Gholamrezayee S, Nikpyee A (2007) Assess the mental health of students with academic factors. J Ment Health 8: 66-161.

15. Mohammadi R (2010) public health nursing. Tehran: Nay publication.

16. Asadzandi (2014) Access to the Sound Heart identifies the concept of spiritual health. J Med Jurisprud 6: 143-173.

17. Shokohy-Yekta M, Zamani N, Parand A (2007) Effect of Anger Management Workshop on mothers of educable mentally retarded children and slow learners. J Rehabilitat 6: 1-3 
Citation: Asadzandi M, Eskandari AR (2018) Religious Evidence-Based Spiritual Self-Care Guidelines in Anger Management. J Health Educ Res Dev 6: 255. doi: 10.4172/2380-5439.1000255

Page 5 of 5

18. Shokohy-Yekta M, Behpajoh A, Ghobari-Bonab B, Zamani (2006) The impact of anger management skills of mothers of educable mentally retarded children and slow learners. J Res on Except Children 10: 1-30.

19. Richey R, Klein JD, Nelson WA (2012) Developmental Research: Studies of Instructional Design and Development, pp: 29-38.

20. Nezamzadeh M, Khademolhosseini M, Mokhtari Nouri J, Ebadi A (2012) Design of Guidelines Evidence- based Nursing Care in Patients with Angina Pectoris. Iran J Crit Care Nurs 4: 169-176.

21. Nehrir B, Rejeh N, Ebadi A (2014) Evidence-based nursing. J Nurs Edu 2: 50-57.

22. Hamilton (2011) National Collaborating Centre for Methods and Tools. Stetler Model of Evidence-Based Practice, pp: 235-80.

23. Dehghan-nayyeri $\mathrm{N}$, Sayalani $\mathrm{KH}$, Movahedi A, Farsi Z, Babamohammadi $H$ (2010) The Practice of Nursing Research Conduct, critique and utilization. Tehran: Andishe rafie 2010.

24. Shekari-Fard M, Asadzandi M, Morovati-Sharif-Abad M, Salari M (2009) The effect of education based on Health Promotion Model (Pender) in reducing risky behaviors of soldiers in his school Valieasr.

25. Asadzandi M, Sekarifard M, Ebadi A, Morovvati Sharif Abad MA, Salari M (2014) Effects of anger management training based on Health Promotion Model on soldiers engage in risky behavior. Iranian J Psych Nurs 2: 68-79.

26. Daniyavi V, Shafiee S (2011) PICU Special Psychiatric Units in Iran, Scientific Journal of Army University of Medical Sciences of the Islamic Republic of Iran 9: 50-57.

27. American psychological Association (2004) Controlling anger before it controls you.

28. Naveedy A, Borjali A (2007) The effects of the implementation of a program of anger management on anger self-regulation skills of high school boys'. J Psychol Res 10: 59-81.
29. Naveedy A (2006) Effect of anger management training on adjustment skills of high school boys of Tehran. Iranian J Clin Psychol Psych 14: 394-403.

30. Aboui Mehrizi M, Tahmassian K, Khosh Konesh A (2010) The impact of Anger Management Training on self-regulation skills anger and conflict between parents with teen girls' middle school in Tehran. J Family Res 6: 393-404.

31. Eskandari GH, Asadzandi M, Khadem M, Ebadi A (2016) Design and validation of Religious evidence-based guidelines for spiritual care, based on Sound heart model in patients. Master's Thesis Nursing. Nursing School Baqiyatallah.

32. Asadzandi M (2016) Spiritual self-care. Tehran, Resaneh-Takhassosi Publication.

33. Asadi M, Asadzandi, Ebadi A (2014) Effects of spiritual care based on Ghalb Salim nursing model in reducing anxiety of patients undergoing CABG surgery, Iran J Critical Care Nurs 6: 142-151.

34. Asadzandi M (2014) The effect of spiritual care based on Ghalbe Salim mode on the sleep quality of the patients with coronary artery disease. Iran J Critical Care Nurs 7: 94-103.

35. Asadzandi M (2015) Sound Heart: Spiritual Nursing Care Model from Religious Viewpoint. J Religion Health 54: 104-130.

36. Asadzandi M (2016) Spiritual counseling. Tehran, Resaneh-Takhassosi Publication.

37. Asadzandi M (2017) Professors, spiritual characteristics for role- modeling education. J Edu Strategies Med Sci 10: 23-35.

38. Mirzaee R, Raeasi Z, Kazemi H (2013) The effectiveness of problem-solving skills training, anger management on depression in prisoners. J Med Sci Sadri, pp: 55-64.

39. Nightie H, Adlib Rod N, Noorani Poor R (2010) The effectiveness of emotional intelligence training on students' aggression. Journal of Kermanshah University of Med Sci 3: 12-25. 